\title{
REAVALIANDO CULTURA E POBREZA
}

Tradução de Markus Hediger

A cultura está de volta à pauta da pesquisa sobre a pobreza. Ao longo da década passada, sociólogos, demógrafos e até mesmo economistas começaram a indagar o papel da cultura em muitos aspectos da pobreza e até a basear-se de forma explícita em fatores culturais para explicar o comportamento da população de baixa renda. Um exemplo é Prudence Carter (2005) que, com base em entrevistas com estudantes provenientes de minorias pobres, argumenta que o empenho de crianças pobres na escola depende em parte de suas crenças culturais sobre as diferenças entre as minorias e a maioria. Annette Lareau (2003), após estudar famílias pobres, da classe trabalhadora e da classe média, conclui que, ao longo de suas vidas, é possível que as crianças pobres possam ser menos bem-sucedidas, em parte porque seus pais têm mais compromisso com o "crescimento natural" do que com o "cultivo orquestrado" como seu modelo cultural para a criação de filhos. Mario Small (2004), com base em um trabalho de campo realizado em um complexo habitacional, em Boston, argumenta que a relutância de pessoas pobres em participar de atividades que beneficiem a comunidade possa ser explicada, em parte, pela forma com que se apercebem culturalmente de seu bairro. David Harding $(2007,2010)$ recorre a dados de pesquisas e entrevistas qualitativas com adolescentes quando argumenta que o comportamento sexual de adolescentes pobres depende, em parte, do grau de heterogeneidade cultural em seus bairros. Tomando o trabalho de outros estudiosos como fundamento, os economistas George Akerlof \& Rachel Kranton (2002) argumentam que o investimento de estudantes em sua educação depende, em parte, de sua identidade cultural, com diferenças de êxito entre "atletas", nerds e "maconheiros". E William Julius Wilson, em seu livro mais recente (2009a), argumenta que a cultura ajuda a explicar como afro-americanos pobres reagem às condições estruturais por eles vivenciadas.

Estes e outros estudiosos começaram a explorar um assunto que foi abandonado há muito tempo. A última geração de estudos sobre o relacionamento pobreza-cultura tem sido identificada primeiramente, para melhor ou para pior, com o modelo da "cultura de pobreza", de Oscar Lewis (1966), e com o relatório 
sobre a família negra, de Daniel Patrick Moynihan (1965). Lewis argumentou que a pobreza prolongada geraria uma série de atitudes, convicções, valores e práticas culturais, e que essa cultura de pobreza tenderia a se perpetuar ao longo do tempo, mesmo se as condições estruturais, que inicialmente deram origem a ela, mudassem. Moynihan argumentou que a família negra encontrava-se presa em uma rede de patologias, resultante dos efeitos cumulativos da escravidão e da subsequente pobreza estrutural que caracterizou a experiência de muitos afro-americanos (ver também Banfield, 1980).

A geração emergente de estudiosos da cultura muitas vezes faz questão de se distanciar da anterior, e por boas razões. Os primeiros eram repetidamente acusados de "culpar as vítimas" por seus problemas, porque pareciam insinuar que as pessoas poderiam sair da pobreza se mudassem a sua cultura (Ryan, 1976). Como foi documentado por muitos, na época, o agitado ambiente político dissuadiu muitos estudiosos jovens de estudarem a cultura no contexto da pobreza. Até mesmo as pesquisas sobre a cultura com maior afinidade teórica, como a de Ulf Hannerz (1969) ou a de Charles Valentine (1968), que atraíram muitos seguidores, não conseguiram conter o êxodo. Na verdade, os cientistas só voltaram a levantar esse tipo de perguntas após a publicação de The truly disadvantaged, de Wilson (1987; Small \& Newman, 2001). Esse interesse renovado tornou-se possível, em parte, pelo ressurgimento do interesse na cultura pelas ciências sociais em geral.

Os estudiosos contemporâneos raramente alegam que a cultura se perpetuará por muitas gerações, independentemente de mudanças estruturais, e eles praticamente nunca usam o termo "patologia". Mas a nova geração de estudiosos também concebe a cultura de maneiras substancialmente diferentes. Ela tipicamente rejeita a noção de que a pobreza das pessoas possa ser explicada por meio de seus valores. Muitas vezes, ela reluta em fazer uma distinção clara entre explicações "estruturais" e "culturais", devido à utilidade, cada vez mais questionável, dessas antigas distinções. ${ }^{1}$ Normalmente, ela não define cultura de forma tão compreensiva como Lewis, mas cuidadosamente distingue entre valores e percepções e entre atitudes e comportamento. Quase sempre rejeita as noções de que membros de um grupo ou de uma nação compartilhem "uma cultura", ou que a cultura de um grupo seja mais ou menos coerente ou internamente consistente. Em muitos casos, suas noções de cultura tendem a ser definidas de modo mais restrito, com mais facilidade de serem medidas e de serem refutadas com maior plausibilidade. Como discutiremos mais adiante, esta nova geração de estudiosos também tende a se basear em uma literatura completamente diferente: o grande corpo de novas pesquisas que surgiu na antropologia e na sociologia culturais ao longo dos últimos 30 anos. 
Apesar desse arranco em atividades científicas, o futuro permanece incerto. Enquanto os cientistas mencionados acima têm procurado injetar a análise cultural na pesquisa sobre a pobreza, outros permanecem profundamente céticos e até mesmo antagonistas em relação a esse tipo de esforços. Hoje, muitos cientistas sensatos insistem que a cultura é, no melhor dos casos, epifenomênica, algo que pode ser explicado, como o faz a persistente teoria marxista, por condições estruturais. Outros continuam desconfiando das intenções políticas dos novos cientistas culturais, e as acusações de que eles "culpem a vítima" não desapareceram do discurso contemporâneo. Além do mais, os estudiosos da pobreza que estudam a cultura não constituem uma escola de pensamento, um grupo, nem mesmo uma rede - não publicaram uma agenda coerente, nem assumiram um compromisso de estudarem essas questões no futuro próximo. Não existe uma terminologia comum ou um conjunto de questões preestabelecido. O assunto pode muito bem desaparecer da consciência científica tão rapidamente quanto surgiu.

Nosso objetivo aqui é fazer um balanço dessa literatura emergente; é identificar questões que permanecem sem resposta; e defender a posição de que o estudo judicioso da cultura, com fundamento teórico e base empírica, pode e deve ser uma componente permanente da agenda da pesquisa sobre a pobreza. Começaremos identificando as razões científicas e políticas pelas quais os estudiosos da pobreza deveriam preocupar-se profundamente com a cultura. Então, abordaremos uma pergunta difícil - o que é "cultura"? - e argumentaremos que sociólogos e antropólogos culturais, com a finalidade de entenderem o processo de criação de significado, desenvolveram pelo menos sete instrumentos analíticos distintos, mesmo que parcialmente coincidentes, que poderiam ajudar a responder perguntas sobre casamento, educação, vizinhanças, participação em comunidades e outros tópicos centrais ao estudo da pobreza.

\section{POR QUE ESTUDAR CULTURA?}

\section{Motivações científicas}

Estudos sobre pobreza devem levar em conta a cultura por pelo menos três razões. A primeira é entender melhor por que as pessoas reagem à pobreza da maneira como o fazem - tanto em relação a como lidam com ela quanto a como escapam dela.

Por que as pessoas lidam com a pobreza da maneira como o fazem? A literatura sobre como os indivíduos reagem a adversidades ou privações materiais é ampla, e foram identificadas uma séria de estratégias para lidar com elas: o uso de laços familiares, a troca de bens dentro de redes de amizade, a procura de ajuda do Estado e de organizações privadas, mudanças de domicílio e outros (Edin \& Lein, 1997; Newman \& Massengill, 2006). Mas há diferenças substanciais 
na estratégia escolhida, e parte dessa heterogeneidade resulta provavelmente de fatores culturais. Por exemplo, os pesquisadores na área de imigração demonstraram que imigrantes pobres muitas vezes criam associações de crédito rotativas a fim de gerar recursos acessíveis ao grupo (Portes, 1998; ver também Sanyal, 2009, sobre associações de microcréditos em um contexto internacional). Uma pergunta importante que modelos culturais podem ajudar a responder é por que a criação de associações rotativas é muito mais comum entre imigrantes pobres do que entre os pobres nativos. Perguntas semelhantes - sobre por que indivíduos ou grupos recorrem a laços familiares, organizações formais, redes de troca e outras estratégias - ainda precisam ser respondidas. Alguns sociólogos argumentam que a resiliência das pessoas, inclusive sua capacidade de lidar com o estigma, está ligada à identidade cultural e à associação social (Hall \& Lamont, 2009; Lamont, 2009).

Por que existem diferenças na capacidade das pessoas de escaparem da pobreza? No final das contas, o maior obstáculo para o status de classe média entre os pobres é a própria privação material contínua. Mas há uma variação significativa em comportamento, processos de decisão e resultados entre pessoas que vivem em condições estruturais aparentemente idênticas, como vários pesquisadores têm notado (Hannerz, 1969; Newman, 1999; Small, 2004). O fato de que pessoas igualmente pobres que vivem nos mesmos bairros de pobreza aguda tomam decisões substancialmente diferentes em relação a gravidez, estudos, tráfico, participação na vida comunitária e roubo tem sido repetidamente documentado por etnógrafos (para uma análise recente, ver Newman \& Massengill, 2006). O que explica essa variação? É provável que isso não se deva ao fato de algumas pessoas possuírem um conjunto de valores "errado". $\mathrm{Na}$ verdade, o conjunto "certo" de valores ou crenças pode até sabotar a mobilidade de uma pessoa quando aplicado em um contexto difícil. Veja, por exemplo, a crença no individualismo e responsabilidade pessoal que muitos americanos consideram ser algo positivo. Em uma pesquisa recente, Sandra Smith (2007) demonstrou que esse valor pode, de fato, minar a capacidade de uma pessoa de encontrar um emprego. Sabemos que muitas pessoas encontram empregos por meio da mobilização de suas redes sociais (Granovetter, 1974). Mas em seu estudo sobre a procura de emprego entre homens e mulheres negras e pobres, Smith descobriu que algumas pessoas não usaram suas redes por causa de (entre outras coisas) um forte senso de individualismo que ditava que as pessoas deveriam ter sucesso com base, primeiramente, em seus próprios esforços. Entre os entrevistados de Smith, a decisão de não recorrer aos seus vínculos sociais para conseguir um emprego não resultou de valores "ruins", mesmo que tenha sido determinado, em parte, pela sua cultura. Em segundo lugar, "valores" representam apenas uma das concepções de cultura e, provavelmente, não é aquela com o melhor poder explicativo. Se, por exemplo, chamarmos de cultura o conjunto de estratégias de ação de uma pessoa (como ela procede para 
conseguir vaga em uma faculdade, como cria redes sociais de forma adequada, como pede favores de conhecidos), então aquelas pessoas que não possuem uma estratégia específica enfrentarão mais dificuldades quando precisarem tomar uma decisão específica (Swidler, 1986). Modelos semelhantes do papel da cultura em relação à mobilidade têm sido usados para explicar por que garotos da classe operária costumam procurar empregos típicos da classe operária, e não da classe média (Willis, 1977); e por que apenas alguns homens pobres da classe operária tentam se mudar para outro bairro e outros, não (Whyte, 1943). O estudo contínuo de como as populações de baixa renda conferem sentido às suas experiências e opções é essencial para o desenvolvimento de explicações melhores para como elas conseguem escapar à pobreza.

Uma segunda razão para o estudo de cultura é derrubar mitos existentes sobre as orientações culturais dos pobres. A tese da "cultura da pobreza" tem sido amplamente criticada, já desde sua aparição, por causa de suas muitas inconsistências teóricas (por exemplo, Valentine, 1968). Mas precisamos de trabalho empírico básico para avaliar convicções bastante triviais sobre as orientações culturais dos pobres ou de minorias étnicas. John Ogbu, por exemplo, argumentou que estudantes negros pobres, em parte como reação àquilo que eles entendiam como oportunidades negadas, desenvolveram uma cultura de oposição que condenava a execução de trabalhos escolares como "atividade branca" (Fordham \& Ogbu, 1986; Obgu, 1978). Mas, mediante uma série de pesquisas recentes, os estudiosos que examinaram a teoria, tomando como base dados representativos nacionais, pouco encontraram que a comprovasse (Cook \& Ludwig, 1998; Ainsworth-Darnell \& Downey, 1998; ver, porém, Fryer \& Torelli, 2005). (Fato é que, levando em conta as diferenças socioeconômicas, os estudantes negros tendem a apresentar mais atitudes pró-escolares). Avaliações semelhantes referentes a paternidade, casamento, trabalho e mobilidade precisam ser feitas. O desenvolvimento de uma compreensão mais completa das condições que produzem e mantêm a pobreza requer uma análise empírica mais detalhada e mais precisa de como os pobres conferem sentido às suas situações, opções e decisões atuais, e de como as explicam.

Uma terceira razão para que pesquisadores da pobreza estudem a cultura é o desenvolvimento e o esclarecimento exato daquilo que entendem quando falam de cultura - independentemente de acreditarem se isso ajudará a explicar um resultado. Durante muito tempo, a cultura tem sido tratada como um "terceiro trilho" pela pesquisa sobre a pobreza, tanto que ela se transformou essencialmente na caixa-preta que agora precisa ser aberta. Neste empreendimento, os pesquisadores da pobreza deveriam ler, criticar e pôr em prática o trabalho dos sociólogos e antropólogos culturais. Esta tarefa será difícil: a literatura sobre a pobreza e a literatura sobre a cultura, são, muitas vezes, produzidas em mundos intelectuais substancialmente diferentes, mundos que envolvem interlocutores, teorias de comportamento, estilos de pensamento 
e padrões de evidência diferentes. Tradicionalmente, o primeiro universo não incluía apenas sociólogos, mas também economistas, cientistas políticos e demógrafos; ele dava preferência à evidência quantitativa; valorizava a clareza e operava tendo em vista a solução de problemas sociais. O segundo universo tem incluído humanistas, antropólogos, historiadores e sociólogos; favorecia a análise interpretativa ou qualitativa e incentivava o desenvolvimento de novas teorias. Como resultado disso, obras importantes daqui muitas vezes tiveram pouco impacto ali.

Não obstante, é possível exagerar as diferenças entre essas áreas. Muitas das obras mais importantes sobre a pobreza têm sido de natureza qualitativa ou interpretativa (Newman \& Massengill, 2006), e alguns dos clássicos da sociologia da cultura apoiaram-se em análises quantitativas (Bourdieu, 1984). Fato é que muitos estudiosos da pobreza se sentem cada vez mais à vontade com múltiplos métodos e estilos de pensamento. Tais convergências são evidentes não apenas no volume 619 da The Annals of the American Academy of Political and Social Science (2008), mas também em números recentes da revista (2009; 2010) que mostram desenvolvimentos na sociologia cultural e nos estudos da pobreza. ${ }^{2}$ Nos últimos anos, os economistas também começaram a trabalhar com conceitos culturais, a fim de entender a origem das crenças e preferências dos indivíduos (Rao \& Walton, 2004). Guiso, Sapienza \& Zingales (2006), por exemplo, desenvolvem um modelo no qual crenças e normas no nível de grupo afetam as convicções e preferências individuais que, por sua vez, afetam resultados e processos de decisão econômicos. Akerloff \& Kranton $(2000,2002)$ usam o conceito de identidade para desenvolver um modelo em que indivíduos demonstram preferências por um comportamento que é consistente com suas identidades de grupo e que tiram proveito deste tipo de comportamento (ver também Benabou e Tirole, 2006). E Amartya Sen (1992) desenvolveu o conceito de capacidades para entender aspectos de desigualdade no bem-estar que não são explicados pela noção tradicional de utilidade. Esses desenvolvimentos são promissores e podem sugerir possibilidades para um diálogo interdisciplinar melhor.

\section{Motivações políticas}

Pesquisadores e outras pessoas interessadas em política devem se preocupar com a cultura por várias razões. Em primeiro lugar, ignorar a cultura pode levar a uma política ruim. O antropólogo Harragin Simon (2004), por exemplo, examinou a implementação de políticas de ajuda alimentar no sul do Sudão para enfrentar a fome entre os Dinka, que começou em 1998. As organizações de ajuda criaram um programa específico destinado apenas àqueles com sinais de subnutrição avançada. As autoridades locais, no entanto, reorganizaram a ajuda internacional e passaram a redistribuí-la à população geral ao longo das linhas de parentesco por meio de seus chefes de família. Muitos que estavam com fome, mas não sofriam de subnutrição, também receberam ajuda porque 
alguns membros da sua família estavam subnutridos. As organizações tentaram combater esta prática, considerando-a evidência de corrupção e disfunção local. Mas os Dinka operam dentro de um sistema cultural que, apesar de ser igualitário, também é baseado em critérios de parentesco e dentro do qual os alimentos são sempre distribuídos pelos chefes da família e compartilhados em partes iguais entre todos os membros das grandes famílias. Além disso, de acordo com Harragin, a única razão pela qual a fome severa surgiu em 1998, e não já em 1997, foi que os chefes locais redistribuíram para seus parentes os estoques de alimentos cada vez menores de forma equitativa e sempre atentos aos necessitados. A mudança dessas práticas culturais agora era inviável, e poucos beneficiários, em 1998, não importando quão pobres, teriam guardado para si a ajuda destinada aos outros membros da família que, um ano antes, os tinham ajudado a sobreviver. Harrigan sugere, e nós tendemos a concordar, que uma política mais consciente em termos culturais - uma política projetada para funcionar dentro das estruturas de parentesco e dos costumes locais referentes à propriedade, em vez de (inadvertidamente) tentar anulá-las - teria sido mais eficaz e teria evitado as acusações de corrupção que acabaram manchando o esforço de ajuda. ${ }^{3}$

Outro exemplo pode ser visto entre os estrategistas políticos nos Estados Unidos. Nos últimos anos, os políticos têm lançado "campanhas" pró-casamento para mudar as atitudes culturais em relação ao casamento entre os pobres, baseando-se na crença de que os pobres apresentam um índice maior de natalidade entre mães solteiras porque estas não valorizam o casamento tanto quanto as pessoas da classe média. Mas Kathryn Edin e Maria Kefalas (2005) entrevistaram mais de uma centena de mães de baixa renda e descobriram que, ao contrário, muitas delas valorizam o casamento - na verdade, tinham o casamento em tão alta estima que elas hesitavam em se casar, porque acreditavam que tanto elas quanto seus parceiros precisavam estar preparados emocional e financeiramente para ele. Infelizmente, muitas das mulheres tinham poucas esperanças de que seus parceiros algum dia se transformariam em "material de casamento", de tal forma que a espera pelo casamento as teria exposto ao alto risco de nunca se tornarem mães. Independentemente de como os estrategistas políticos avaliem a sensatez de tais decisões, supondo que as mães da pesquisa de Edin e Kefalas sejam representativas para as mães de baixa renda, então as políticas destinadas a fazer com que as mães deem mais valor ao casamento estão simplesmente tentando convencer as pessoas de algo em que elas já acreditam.

As pessoas que se preocupam com a política também devem se preocupar com a cultura, já que ela influencia os processos de decisão das elites políticas que acabam afetando os pobres. Entre as elites políticas incluímos os estudiosos, jornalistas e especialistas que discutem as políticas da pobreza, os ativistas, advogados, acadêmicos e profissionais que afirmam falar em nome 
dos pobres, e os legisladores, os empregadores e os líderes de organizações sem fins lucrativos que, de uma forma ou de outra, tomam decisões políticas que afetam as condições dos pobres. O discurso público sobre a pobreza e as políticas resultantes desse discurso são, eles próprios, produtos culturais, sujeitos aos caprichos, preferências, preconceitos, crenças, posturas e orientações das elites políticas. Tanto o discurso quanto a política refletem suposições profundamente arraigadas (mesmo que muitas vezes inconsistentes) sobre os objetivos da política e, especialmente, sobre trabalho, responsabilidade, serviço, agência, "merecimento" e a estrutura de oportunidade. Tais circunstâncias são particularmente importantes no âmbito da legislação e da política pública. Legisladores não fazem política meramente com base em pesquisas de opinião pública (Kingdon, 1984; Stone, 1989). Somers \& Block (2005), por exemplo, documentaram que, em vários momentos da história, a política da pobreza refletiu a influência de uma ideia particular, por eles chamada de tese da perversidade, segundo a qual a ajuda governamental aos pobres, na verdade, aumenta a pobreza mediante a criação de dependência. Mais recentemente evocada por Murray (1984) em Losing ground e institucionalizada nas reformas de previdência social do final dos anos 1990, a tese da perversidade teve um papel central nas reformas maltusianas da lei inglesa de ajuda social aos pobres na década de 1830 (ver também Bullock, 2008). Essas ideias divergem substancialmente de país para país, e constituem parte importante do universo de alternativas que as elites políticas avaliam; elas determinam os parâmetros sob os quais os debates políticos ocorrem e as decisões políticas são tomadas (Steenland, 2006; O'Connor, 2001).

Uma terceira razão relacionada à política para estudar a cultura é que, para melhor ou pior, a cultura já faz parte do discurso político sobre trabalho, casamento, crime, bem-estar, moradia, paternidade e uma série de outras condições relacionadas à pobreza. Ela participa do debate em ambos os lados do espectro político, não apenas na direita. Durante a campanha presidencial de 2008, Barack Obama argumentou que parte do problema com os adolescentes é que os pais deixaram de assumir a responsabilidade por seus filhos, deixando as mães e crianças à mercê delas mesmas. O então candidato Obama cedeu pouco diante daqueles que objetaram dizendo que a pobreza minava a paternidade - ele permaneceu firme em sua convicção de que os pais precisavam mudar sua atitude (cultural) em relação à paternidade. (De fato, alguns críticos acreditavam que ele estava atacando injustamente os afro-americanos, já que, muitas vezes, repetia esses argumentos quando fazia palestras em igrejas com público negro.) Independentemente da posição de um estudioso sobre esse ou outros assuntos nas discussões públicas sobre a cultura, a recusa de estudar, refletir e comentar a relação da cultura com a pobreza não vai fazer com que os debates desapareçam. 
Os estudiosos da pobreza e desigualdade também invocam a cultura nos debates públicos, de forma seletiva. Orlando Patterson (2000) observou que os estudiosos da desigualdade, que tendem a se inclinar para a esquerda do espectro político em questões de política, muitas vezes relutam em recorrer a fatores culturais para explicar muitos aspectos da pobreza ou da desigualdade social. No entanto, eles se serviram ardorosamente de explicações culturais durante a recente controvérsia pública sobre as diferenças raciais em QI. Após Herrnstein \& Murray (1994) terem argumentado que as diferenças raciais nos resultados dos testes de QI seriam, em parte, geneticamente determinadas, os pesquisadores responderam com uma série de argumentos, muitos dos quais invocavam explicitamente fatores culturais: diziam, por exemplo, que os testes de QI frequentemente são tendenciosos em termos culturais e que as crianças negras e brancas talvez ajam em ambientes culturais que incentivam diferentes estilos de aprendizagem. A invocação seletiva de explicações culturais só prejudica o potencial da pesquisa nas ciências sociais de informar a discussão política.

\section{Indo em frente}

Alguns reclamam que a defesa do estudo da cultura no contexto da pobreza alimente uma agenda conservadora que visa a culpar as vítimas por seus problemas. Esperamos ter deixado claro a razão pela qual discordamos fortemente. Nenhum dos três autores deste artigo faz parte da direita do espectro político, mas a nossa orientação política também nem vem ao caso. A pergunta quanto a se, quando e de que forma ferramentas e restrições culturais importam é, em última análise, uma questão empírica, e não política. É também importante fazermos as perguntas certas, e alguns pontos de vista tendiam a "culpar a vítima" porque lhes faltavam evidências suficientes ou faziam as perguntas erradas. Acreditamos que as referências à cultura seriam mais convincentes se elas se fundamentassem na literatura muito mais sofisticada sobre cultura que tem se desenvolvido ao longo das últimas três décadas ou mais.

\section{O QUE É CULTURA?}

Os leitores perceberão que não definimos "cultura", pelo menos não de forma explícita. Optamos por essa abordagem porque a literatura tem produzido definições múltiplas, e é pouco provável que se crie um consenso no futuro próximo. ${ }^{4}$ Diante dessa situação, a melhor abordagem é a pragmática. Hoje, muitos sociólogos culturais têm examinado condições empíricas empregando conceitos específicos e (muitas vezes) bem definidos, tais como frames ou narrativas que, de uma forma ou de outra, são reconhecíveis como "culturais". Enquanto o termo geral "cultura" possa servir como abreviação útil para referir-se a uma constelação de questões à qual os estudiosos da pobreza deveriam 
dar mais atenção, ele, no fim das contas, ofusca mais do que esclarece, pelo menos quando o objetivo é entender um problema específico, como, por exemplo, por que alunos mais pobres dedicam menos tempo aos deveres de casa, ou por que mulheres de baixa renda têm mais filhos fora do casamento. No que segue, esboçamos sete perspectivas diferentes, mas às vezes coincidentes em parte, baseadas em sete conceitos diferentes - valores, frames, repertórios, narrativas, limites simbólicos, capital cultural e instituições - demonstrando assim como uma sensibilidade maior em relação a condições culturais pode enriquecer a nossa compreensão da pobreza. ${ }^{5}$ Acreditamos que o emprego dessas ferramentas analíticas mais restritas e distintas é muito mais útil do que o emprego do conceito de "cultura", que, normalmente, é usado de forma excessivamente vaga.

\section{Valores}

A concepção parsoniana de cultura é, talvez, a mais conhecida entre os pesquisadores da pobreza. Valores especificam os fins aos quais o comportamento é direcionado (em oposição aos meios usados para alcançá-los ou à lente através da qual a ação é interpretada). As proposições centrais à nossa discussão - que valores seriam preditores robustos para o comportamento e que os pobres apresentam valores substancialmente diferentes dos membros da classe média encontram pouco apoio na literatura. Na verdade, existe evidência considerável que indica a adoção ampla de valores convencionais entre os pobres (Young, 2004; Newman, 1999; Edin \& Kefalas, 2005; Dohan, 2003; Hayes, 2003; Carter, 2005; Waller, 2002; Duneier, 1992).

Alguns estudiosos sugeriram modelos alternativos baseados em valores. Entre estes, talvez o mais proeminente seja a "extensão dos valores nas classes baixas" (lower-class value stretch), de Rodman (1963). Rodman argumenta que os pobres não apresentam valores diferentes, mas sim um conjunto de valores mais amplo e um compromisso menor para com eles. Ao testar a teoria, Della Fave (1974) encontrou pouco que a comprovasse (ver também Ainsworth-Darnell \& Downey, 1998). Vários estudiosos, porém, adotaram a noção de mais heterogeneidade entre os pobres, baseados em diferentes concepções de cultura (Hannerz, 1969; Anderson, 1999). Vaisey (2010) defende a importância dos valores no sucesso educacional.

\section{Frames}

A premissa básica por trás da ideia de um frame é que as pessoas agem dependendo de como elas se apercebem cognitivamente de si mesmas, do mundo ou de seus ambientes (ver Goffman, 1974). Um frame (um quadro) é muitas vezes compreendido como uma lente através da qual observamos e interpretamos a vida social. Frames destacam certos aspectos da vida social e escondem ou bloqueiam outros; representam maneiras de entender "como o mundo funciona" 
(Young, 2004). O conceito dos frames é fundamentado na premissa de que indivíduos diferentes vivenciam os mesmos eventos de forma diferente, baseada em suas experiências e conhecimentos anteriores. Os frames codificam expectativas referentes às consequências de comportamento e às relações entre vários aspectos dos nossos mundos sociais. Um frame estrutura a nossa interpretação de eventos e, portanto, a nossa reação a eles. Como conceito, eles têm suas raízes na obra de Schutz (1962), Berger \& Luckman (1966) e Goffman (1974), entre outros.

Ao entendermos os frames que indivíduos ou grupos diferentes empregam em interações sociais e processos de decisão, podemos começar a entender a variação de suas interpretações e compreensões. Small (2002, 2004), por exemplo, analisou a participação comunitária local em um projeto público hispânico de moradia em Boston. O projeto de moradia fora construído após a mobilização política por residentes da comunidade décadas antes. Small descobriu que eram os frames, através dos quais os residentes viam a vizinhança, e não o grau com que valorizavam a participação comunitária, que influenciavam a participação. Aqueles que viam a participação pela lente da história de mobilização política da comunidade demonstravam mais inclinação para participar, enquanto aqueles que viam a comunidade apenas como mais um projeto de habitação não participavam. Além do mais, os residentes que até então não tinham se envolvido só vieram a participar ativamente após enquadrar o seu entendimento de vizinhança em um novo frame. Harding $(2007,2010)$ aplicou o conceito dos frames aos processos de decisão em relacionamentos românticos e gravidez entre adolescentes em vizinhanças desfavorecidas. Os frames referentes à gravidez adolescente definem as consequências sociais e econômicas da maternidade precoce. Baseando-se tanto em dados de pesquisas representativas nacionais quanto em entrevistas qualitativas de três vizinhanças em Boston, ele documentou a grande variedade de frames competidores e conflitantes relativos à gravidez de adolescentes em bairros desfavorecidos. Esses incluem frames convencionais e populares, que enfatizam o potencial da gravidez adolescente de interferir de forma negativa na escola e na carreira, mas também frames alternativos que enfatizam o status social do adulto e a necessidade de assumir responsabilidade que vem com a maternidade.

Esses exemplos ilustram duas contribuições para a pesquisa sobre a pobreza, possibilitadas pelo foco em frames. Primeiro, apesar de a subcultura da perspectiva da pobreza exigir um conjunto uniforme de reações à pobreza, tanto Small como Harding deixam claro que a heterogeneidade é comum e importante. Bairros pobres são heterogêneos em termos culturais e, portanto, apresentam também uma variedade heterogênea de comportamentos e resultados. Tanto Small como Harding rejeitam a noção de que exista uma única e coesa cultura de gueto compartilhada por residentes de bairros de pobreza aguda. Ao contrário, ambos encontram uma variação considerável nos frames dentro desses contextos. 
Segundo, os frames permitem uma conceituação diferente da correlação entre cultura e comportamento. Em vez de uma relação estreita de causa e efeito entre cultura e comportamento, a conceituação da cultura em termos de frames possibilita aquilo que Small $(2002,2004)$ chama de relação "restrição e possibilidade". Em vez de causar o comportamento, os frames o tornam possível ou provável. Assim, a forma como alguém pensa sobre procriação é provavelmente influenciada por outros frames: pelo modo, por exemplo, como alguém percebe oportunidades no âmbito do trabalho ou como pensa em relação à salvação. Os frames definem o horizonte de possibilidades, de projetos da vida individual ou daquilo que é concebível.

\section{Repertórios}

O conceito de repertórios de ação se baseia em duas premissas: primeiro, que as pessoas possuem uma lista ou um repertório de estratégias e ações em suas mentes (como conseguir uma vaga na faculdade, como disparar uma arma, como usar uma camisinha); segundo, que é improvável que as pessoas se envolvam em uma ação a não ser que a estratégia para executá-la faça parte de seu repertório. Hannerz (1969) descreveu o repertório como conjunto de "modos de ação" e significados. Cada indivíduo possui um repertório dessas ferramentas culturais e recorre a elas quando uma ação é exigida. Hannerz argumentou que os residentes de um gueto em Washington, D.C., que ele estudou, tinham acesso tanto a elementos culturais gerais quanto a elementos culturais "específicos ao gueto". A metáfora da "caixa de ferramentas" foi usada por Swidler (1986) para explicar como o repertório funciona. Um repertório é mais um depósito de ideias ao qual se pode recorrer, e menos um sistema de valores ou normas unificado (Swidler, 1986). Swidler argumentou que os pobres não possuem valores diferentes do resto da sociedade, mas, antes, têm acesso a repertórios diferentes, a partir dos quais desenvolvem suas estratégias de ação. Recentemente, essa abordagem foi usada por Van Hook \& Bean (2009) para explicar os comportamentos em relação à assistência social de imigrantes mexicanos. Esses autores demonstraram a importância de repertórios pró-trabalho, em oposição aos repertórios de dependência da assistência social, para essa população.

Os repertórios podem apresentar variações não apenas no conteúdo de seus elementos, mas também no número e na extensão destes. Assim, alguns atores podem ter melhores horizontes de possibilidades porque possuem uma variedade mais ampla de repertórios de ação. Uma variedade mais ampla introduz a possibilidade de contradições. Fato é que a pesquisa cognitiva sugere que não somos apenas capazes, mas que, de fato, frequentemente vivemos com tais contradições, empregando ferramentas diferentes em situações diferentes (DiMaggio, 1997).

Apesar de o conceito dos repertórios apresentar um potencial considerável, ele exige um desenvolvimento teórico e empírico adicional. Lamont 
(1992), em particular, argumenta que a perspectiva dos repertórios ainda não conseguiu explicar por que alguns elementos do repertório são escolhidos para desenvolver um curso de ação enquanto outros não são considerados. Lamont sugere que oportunidades e restrições exercem uma influência sobre essas decisões (Lamont \& Thévenot, 2000). Além disso, existe uma imprecisão terminológica considerável entre estratégias, repertórios, habilidades, hábitos e estilos na formulação de Swidler, o que mina a aplicação do conceito entre os pesquisadores da pobreza.

\section{Narrativas}

A premissa-chave por trás da ideia de narrativas é que pessoas interpretam suas vidas como um conjunto de narrativas, ou histórias, que têm um início, um meio e um fim e que contêm sequências de eventos causalmente interligadas (Somers \& Gibson, 1994; Ewick \& Silbey, 2003; Polletta, 2006). Indivíduos conferem sentido às suas vidas por meio de narrativas sobre suas experiências pessoais, e, como argumentam Ewick \& Silbey, as narrativas são intercambiadas e construídas uma em cima da outra, tornando-se assim "parte de uma corrente de conhecimento sociocultural sobre o funcionamento de estruturas para distribuir poder e desvantagem" (2003: 1328). Somers \& Gibson (1994) argumentam que um aspecto-chave das narrativas é que elas criam vínculos entre partes do mundo social (o que eles chamam de "enredamento"), no lugar de simplesmente categorizá-las. Por essa razão, as narrativas fornecem explicações de como os indivíduos veem a si mesmos em relação aos outros e, por isso, são centrais para a forma como construímos identidades sociais. Elas afetam nossas ações, porque indivíduos escolhem ações consistentes com suas identidades e narrativas pessoais. Muitas vezes, cativam porque apelam à emoção e a experiências humanas compartilhadas.

Para os pesquisadores da pobreza, as narrativas são importantes porque, como histórias que as pessoas contam sobre si mesmas e sobre outros, as narrativas revelam como as pessoas conferem sentido às suas experiências, restrições e oportunidades. Young (2004), por exemplo, estudou as narrativas de mobilidade de homens pobres, jovens e negros em um projeto de moradia no lado oeste de Chicago e revelou uma mudança surpreendente na noção de isolamento social (Wilson 1987, 1996). Os homens jovens que mais se encontravam isolados dos brancos e que menos tinham experimentado algum envolvimento com o mercado de trabalho eram aqueles que apresentavam mais otimismo em relação à igualdade de oportunidade e menos probabilidade de acreditarem que o racismo afetasse suas chances na vida. Apenas aqueles que já apresentavam uma experiência considerável com os brancos citavam preconceitos como obstáculo importante para o avanço econômico. 


\section{Limites simbólicos}

O conceito dos limites simbólicos reconhece que os esquemas de categorização social são construções culturais. Os limites simbólicos são distinções conceituais que traçamos entre objetos, pessoas e práticas. Eles operam como "sistema de regras que guiam a interação influenciando a escolha das pessoas que se encontram e o seu tipo de ato social" (Lamont \& Fournier, 1992: 12). Em resumo, os limites simbólicos constituem um sistema de classificação que define a hierarquia de grupos e as semelhanças e diferenças que existem entre eles. Eles tipicamente acarretam e justificam uma hierarquia de valor moral entre indivíduos e grupos. Os limites simbólicos são uma condição necessária, porém não suficiente para os limites sociais mais facilmente reconhecíveis de segregação residencial e ocupacional, de exclusão racial e de classe e padrões de miscigenação (Lamont \& Molnár, 2002). Assim como as narrativas, os limites simbólicos são essenciais para as identidades sociais, mas enquanto as narrativas focam nos vínculos com outros, os limites simbólicos iluminam o fundamento cultural de divisões de grupos.

Lamont (2000) usa uma análise dos limites simbólicos de homens da classe operária na França e nos Estados Unidos para investigar como eles mesmos se posicionam em relação aos pobres. Nos Estados Unidos, os homens da classe operária fazem uma forte distinção entre eles mesmos e os pobres por intemédio da ênfase de trabalho duro, responsabilidade e autossuficiência em suas autodefinições. Em contraste, os homens da classe operária francesa não estabelecem limites morais tão fortes entre si mesmos e os pobres, mas veem os pobres como colegas trabalhadores momentaneamente excluídos pelas forças do capitalismo (e, por isso, merecedores de apoio). Essas diferenças transnacionais nos limites simbólicos são produto de tradições políticas e culturais diferentes (por exemplo, individualismo nos Estados Unidos versus catolicismo e socialismo na França). Para os estudiosos da política da pobreza, o aspecto importante é que categorias culturais de valor correspondem a diferenças de política nas políticas redistributivas e de assistência social nas duas nações (Steensland, 2006; Dobbin, 1994). O ato de erguer e manter limites simbólicos é chamado de "trabalho de limites". O trabalho de limites inclui a construção de identidade coletiva por meio da diferenciação de si mesmo em relação aos outros, aplicando critérios como traços e experiências comuns, como também um senso de identidade compartilhada.

Enquanto estudos de trabalho de limites e limites simbólicos entre o público mais amplo revelam o papel desses processos no trabalho político e prestação de serviços aos pobres, os estudos de trabalho de limites entre os próprios pobres revelam o grau como estes definem sua proximidade ao mainstream ou à sociedade da classe média. Newman (1999), por exemplo, mostra como funcionários de lanchonetes do tipo fast food no Harlem se definem em oposição aos pobres desempregados, e como eles desenvolvem um senso de 
identidade como trabalhadores moralmente superiores aos desempregados. Anderson (1999) documenta as divisões entre famílias "decentes" e "de rua" em um gueto da Filadélfia. As famílias "decentes" se definem em oposição às famílias "de rua" com base em seu status de empregados no mercado de trabalho formal (versus a economia informal); na disciplina e autocontrole de seus filhos e na condenação de crime, violência, uso de drogas e outros tipos de comportamento que foge às normas.

\section{Capital cultural}

O termo "capital cultural" tem sido usado de muitas maneiras diferentes, significando, às vezes, o conhecimento ou a informação adquirida por meio de experiências sociais e, às vezes - em sua formulação mais original -, os estilos ou gostos associados aos membros da classe alta. Esse tipo de estilos ou gostos é, muitas vezes, expressado e observado de forma inconsciente. Aqui, usamos a definição de Lamont \& Lareau (1988: 56): "Sinais culturais de alto status institucionalizados, ou seja, amplamente compartilhados." O conceito de capital cultural contribui para o nosso entendimento da pobreza e da desigualdade ajudando-nos a explicar como os pais das classes média e alta são capazes de repassar as vantagens para seus filhos por intermédio da familiarização com hábitos e estilos comportamentais que são valorizados pelo sistema educacional. Mesmo que a pesquisa norte-americana inicial sobre o capital cultural tenha focado na familiaridade com a alta cultura (DiMaggio, 1982), os trabalhos mais recentes têm examinado um espectro mais amplo de sinais de alto status. Uma descoberta interessante revela que aversões compartilhadas podem ser um sinal cultural tão importante quanto preferências compartilhadas (Bryson, 1996).

A conceituação original do capital cultural, desenvolvida por Bourdieu \& Passeron (1977), afirma que o sistema escolar usa padrões da classe média para avaliar crianças, assim prejudicando aquelas da classe operária e de famílias pobres que não têm a oportunidade de aprender esse tipo de comportamentos e estilos em casa. Além disso, as crianças da classe operária e de famílias pobres podem vir a avaliar a si mesmas e suas origens de acordo com os padrões da cultura da classe média, vivenciando assim uma "violência simbólica" que afeta sua autoestima.

Uma descoberta-chave recente na pesquisa sobre o capital cultural e a pobreza diz que ambientes culturais diferentes privilegiam gostos, hábitos e estilos diferentes. Carter (2005) desenvolve o conceito do "capital cultural não dominante", ou seja, gostos musicais, estilos de moda e padrões de fala que sinalizam "autenticidade cultural" em comunidades de minorias pobres. $\mathrm{O}$ capital cultural não dominante sinaliza filiação ao grupo entre colegas, enquanto os adolescentes que não demonstram facilidade no uso desses sinais culturais são retratados como indivíduos "de comportamento branco". As descobertas de Carter enfatizam a discordância entre sinais culturais favorecidos pelas insti- 
tuições de classe média e aqueles que são necessários para inclusão, identidade e apoio social em comunidades urbanas pobres.

Lareau (2003) descreve os processos pelos quais os pais da classe média repassam as vantagens de capital cultural para os seus filhos. Estes pais praticam aquilo que Lareau chama de "cultivo orquestrado", providenciando aos seus filhos muitas atividades estruturadas que lhes ensinam a funcionar dentro de ambientes institucionalizados e falando com eles de forma que encoraje sua participação, em vez de controlá-los. Em contraste, os pais pobres e da classe operária praticam o "crescimento natural": dão aos filhos muito tempo livre não estruturado, interagem com membros da família e da comunidade e ensinam aos filhos a se comportarem de forma respeitosa e a ficarem calados. Os filhos dessas famílias aprendem a ser autossuficientes e socialmente competentes, mas os filhos de classe média aprendem competências sociais que são mais valorizadas pelo sistema educacional e pelo mercado de trabalho.

\section{Instituições}

Dentre os sete conceitos aqui discutidos, o das "instituições" seja, talvez, o conceito empregado de forma mais ampla na sociologia (Powell \& DiMaggio, 1991). Infelizmente, existe uma variedade substancial de definições, das quais algumas se parecem muito com vários conceitos de cultura discutidos acima. Por isso, não afirmamos aqui que os conceitos de instituição cultural possam ser facilmente comparados com os outros. Muitas vezes, porém, existe uma diferença na unidade de análise. Os outros conceitos localizam tipicamente a cultura em indivíduos, grupos ou relações interpessoais; instituições, por sua vez, são localizadas ou em organizações ou na sociedade como um todo. Em uma análise de teorias institucionais antigas e novas, Scott (1995) identifica três conceitos de instituição diferentes: a instituição é definida como conjunto de regras formais de comportamento codificadas como leis ou regulamentações, de normas de comportamento adequado impostas por meio de sanções informais e de noções inquestionadas que simplesmente estruturam ou enquadram (no sentido explicado acima) a forma como os atores se apercebem de suas circunstâncias.

Usamos dois exemplos para ilustrar. Small (2009) foca em organizações e nos dois primeiros conceitos de instituição (regras e normas); Steensland (2006), na sociedade como um todo e no terceiro conceito (noções inquestionadas). Ao estudar as redes sociais formadas por mães em creches na cidade de Nova York, Small (2009) investigou por que algumas mães criavam muitos vínculos com outras mães, enquanto outras interagiam pouco. Descobriu que parte da resposta se encontra nas regras institucionais pelas quais as diversas creches regulamentavam o comportamento dos pais, como, por exemplo, as regras referentes a entrada e saída das crianças na creche, o número de excursões que a creche fazia a cada ano e a organização de associações formais de pais, que ofereciam oportunidades diferentes para encontros. Steensland (2006) perguntou 
pelos motivos responsáveis pela ascensão e queda das propostas de políticas de renda garantida nas décadas de 1960 e 1970. Descobriu que (entre outras coisas) a distinção inquestionada entre os "merecedores" e "desmerecedores" estava tão solidamente institucionalizada em programas existentes, que ela reforçava os limites reconhecidos entre as categorias dos pobres, assim tornando difícil a realização de propostas que não respeitavam esses limites.

Ao discutirmos estes conceitos, esperamos encorajar um diálogo dinâmico e produtivo entre os estudiosos da pobreza, não apenas na sociologia, mas nas ciências sociais como um todo. Acreditamos que um empenho interdisciplinar mais sério é essencial para que os pesquisadores possam se libertar de caminhos analíticos previsíveis traçados pelas literaturas existentes. No final das contas, nossa meta é trabalhar para identificar novas abordagens e novas perguntas que resultem em um entendimento mais compreensivo, preciso e complexo dos processos e mecanismos que levam à reprodução da pobreza. Repetimos que não negamos a importância de condições macroestruturais como a concentração de renda e riqueza, a segregação espacial de classes e grupos raciais ou a persistente migração internacional de trabalho e capital. Em vez disso, argumentamos que, já que a ação humana é restringida e, ao mesmo tempo, possibilitada pelo significado que as pessoas conferem às suas ações, essas dinâmicas deveriam se tornar centrais para a nossa compreensão da produção e reprodução da pobreza e da desigualdade social.

Artigo recebido para publicação em junho de 2011. 
Mario Luis Small é PhD pela Universidade de Harvard e professor de Sociologia da Universidade de Chicago. Seus interesses de pesquisa incluem pobreza urbana, desigualdade e cultura, e redes interpessoais. Publicou, entre outros, Villa Victoria: the transformation of social capital in a Boston barrio (2004), e Unanticipated gains: origins of network inequality in everyday life (2009).

David J. Harding é PhD pela Universidade de Harvard e professor associado do Departamento de Sociologia da Universidade de Michigan. Seus interesses de pesquisa incluem desigualdade, pobreza urbana, efeito vizinhança e reinserção de presos. Publicou Rampage: the social roots of school shootings (2004), em coautoria, e Living the drama: community, conflict, and culture among inner-city boys (2010).

Michèle Lamont é professora de Estudos Europeus na cátedra Robert I. Goldman e professora de Sociologia e de Estudos Africanos e Afro-Americanos na Universidade de Harvard. Seus interesses acadêmicos se concentram em conceitos compartilhados de valor e seu impacto sobre as hierarquias em diversos domínios sociais. Entre suas publicações recentes estão How professors think: inside the curious world of academic judgment (2009), e, em coautoria, Social knowledge in the making (2011). 


\section{NOTAS}

Este artigo é uma versão adaptada, com permissão dos autores, do original intitulado Reconsidering culture and poverty que serve de introdução ao volume homônimo de The Annals of the American Academy of Political and Social Science, 2010, 629/1. Seu conteúdo, num total de 11 artigos, pode ser encontrado no seguinte endereço: http://ann.sagepub. com/content/629/1.toc. () Sage Publications (N. E.).

1 Parte do problema é que, na sociologia, o termo "estrutura" foi definido de várias maneiras diferentes: como restrições econômicas enfrentadas por um indivíduo (definição esta encontrada em grande parte da literatura sobre a pobreza), como modo de produção que caracteriza uma sociedade (encontrada na literatura neomarxista) ou como sistema de pontos de interseção e vínculos que caracterizam um conjunto de relações (assim definido pela literatura sobre redes sociais), entre outros. Quando aplicam a distinção estrutura-cultura em sua forma mais simples e direta, os estudiosos argumentam que o comportamento dos pobres resulta não de seus valores (cultura), mas da falta de recursos financeiros (estrutura), independente da questão se essa privação é individual (como no caso de necessidade material) ou coletiva (como no caso de escolas que sofrem falta de recursos ou bairros isolados em termos de organização). Steinberg (1981), por exemplo, usou um argumento desse tipo ao rejeitar a ideia de que diferenças étnicas em comportamento resultassem de diferenças culturais entre grupos étnicos. Por razões que discutiremos ao longo deste artigo, tendemos a concordar que às noções como "culturas étnicas" ou "cultura de gueto" falta poder explanatório. Mas, como discutiremos a seguir, a variação substancial em reações a restrições financeiras semelhantes (sejam elas de caráter individual ou coletivo) deixa claro que esse tipo de restrição material não pode explicar tudo. Está em jogo a descoberta de explicações alternativas a serem reveladas, inclusive explicações referentes às restrições em repertórios culturais aos quais os indivíduos têm acesso. Acrescentamos que, na sociologia cultural, alguns estudiosos estabelecem uma diferença entre estrutura social (definida em uma das maneiras citadas acima) e estrutura cultural, definida como significado compartilhado e pressuposto. 
2 Ver Cultural sociology and its diversity (The Annals of the American Academy of Political and Social Science, 2008), em especial os artigos de Skrentny (2008) e Charles (2008), e The Moynihan Report revisited: lessons and reflections after four decades (The Annals of the American Academy of Political and Social Science, 2009), em particular o artigo de Wilson (2009b).

3 De forma semelhante, Ann Swidler (2009), empregando ferramentas da sociologia cultural, vem estudando a concordância institucional entre políticas e suas populações-alvo na prevenção da AIDS em várias sociedades africanas.

4 Alguns definem cultura como os valores de um ator; outros, como categorias cognitivas por meio das quais o ator percebe (mais do que avalia) o mundo. Alguns acreditam que ela reside na mente dos indivíduos; outros, que, antes, é necessariamente um traço de grupos e não de indivíduos. Cinquenta anos atrás, talvez os sociólogos tivessem, sem fazer alarde, confiado na dominância de Talcott Parsons e recorrido a seu conceito de cultura como normas e valores comuns à sociedade e necessárias para seu sustento e reprodução. Antropólogos talvez tivessem encontrado consolo em uma concepção de cultura mais ou menos acordada, mesmo que um tanto ambígua, derivada de Edward Tylor (1871): "aquele complexo todo que inclui conhecimento, crença, artes, moral, lei, costume e qualquer outra capacidade e hábito adquirido pelo homem como membro da sociedade." Mas mesmo na época, o acordo era mais imaginário do que real. Alfred Kroeber \& Clyde Kluckhon em seu livro Culture: a critical review of concepts and definitions (1952), gastaram quase 400 páginas descrevendo, destilando e acessando as muitas definições de cultura que a antropologia empregara até então, esmagando o leitor sob o incrível número de assuntos (historicidade, normas, psicologia, linguagem etc.) que os conceitos de cultura tentaram compreender. Os 50 anos que se passaram desde então produziram novos vocabulários completos (frames, hábito, doxa, estruturação etc.) que tornariam uma versão daquele volume ainda mais esmagador.

5 Uma revisão mais detalhada pode ser encontrada em Lamont \& Small (2008). 


\section{REFERÊNCIAS BIBLIOGRÁFICAS}

Ainsworth-Darnell, James \& Downey, Douglas. Assessing the oppositional culture explanation for racial/ethnic differences in school performance. American Sociological Review, 1998, 63, p. 536-553.

Akerloff, George \& Kranton, Rachel. Economics and identity. Quarterly Journal of Economics, 2000,115/3, p. 715-753.

Identity and schooling: some lessons for the economics of education. Journal of Economic Literature, 2002, 40, p. 1167-2101.

Anderson, Elijah. Code of the street: decency, violence, and the moral life of the inner city. Nova York: Norton, 1999.

Banfield, Edward. The unheavenly city: the nature and future of our urban crisis. Boston: Little, Brown, 1970.

Benabou, Roland \& Tirole, Jean. Belief in a just world and redistributive politics. Quarterly Journal of Economics, 2006, 121/2, p. 699-746.

Berger, Peter L. \& Luckman, Thomas. The social construction of reality: a treatise in the sociology of knowledge. Garden City, NY: Doubleday, 1966.

Bourdieu, Pierre. Distinction: a social critique of the judgment of taste. Cambridge, MA: Harvard University Press, 1984.

\& Passeron, Jean-Claude. Reproduction in education, society and culture. Beverly Hills, CA: Sage, 1977.

Bryson, Bethany. Anything but heavy metal: symbolic exclusion and musical dislikes. American Sociological Review, 1996, 61/5, p. 884-899.

Bullock, Heather E. Justifying inequality: a social psychological analysis of beliefs about poverty and inequality. In: Lin, Ann C. \& Harris, David R. (orgs.). The colors of poverty. Nova York: Russell Sage Foundation, 2008.

Carter, Prudence. Keepin' it real: school success beyond black and white. Nova York: Oxford University Press, 2005.

Charles, Maria. Culture and inequality: identity, ideology, and difference in "postascriptive society". The Annals of the American Academy of Political and Social Science, 2008, 619/1, p. $41-58$. 
Cook, Phillip \& Ludwig, Jens. The burden of "acting white": do black adolescents disparage academic achievement?. In: Jencks, Christopher \& Phillips, Meredith (orgs.). The black white test score gap. Washington, DC: Brookings Institution, 1998, p. 375-401.

Della Fave, Richard. Success values: are they universal or class differentiated?. American Journal of Sociology, 1974, 80/1, p. 153-169.

DiMaggio, Paul. Cultural capital and school success: the impact of status culture participation on the grades of U. S. high school students. American Sociological Review, 1982, 47, p. 189-201.

. Culture and cognition. Annual Review of Sociology, 1997, 23, p. 263-87.

Dobbin, Frank. Forging industrial policy: the United States, Britain, and France in the Railway Age. Nova York: Cambridge University Press, 1994.

Dohan, Daniel. The price of poverty: money, work, and culture in the Mexican American barrio. Berkeley: University of California Press, 2003.

Duneier, Mitchell. Slim's table: race, respectability, and masculinity. Chicago: University of Chicago Press, 1992.

Edin, Kathryn \& Kefalas, Maria. Promises I can keep: why poor women put motherhood before marriage. Berkeley: University of California Press, 2005.

Edin, Kathryn \& Lein, Laura. Making ends meet: how single mothers survive welfare and lowwage work. Nova York: Russell Sage Foundation, 1997.

Ewick, Patricia \& Silbey, Susan. Narrating social structure: stories of resistance to legal authority. American Journal of Sociology, 2003, 108/6, p. 1328-1372.

Fordham, Signithia \& Ogbu, John. Black students' school success: coping with the burden of "acting white". Urban Review, 1986, 18/3, p. 176-206.

Fryer, Roland G. \& Torelli, Paul. An empirical analysis of acting white. NBER Working Paper $n^{\circ}$ 11.334. Cambridge, MA: National Bureau of Economic Research, 2005.

Goffman, Erving. Frame analysis. Cambridge, MA: Harvard University Press, 1974. 
Granovetter, Mark. Getting a job: a study of contacts and careers. Cambridge, MA: Harvard University Press, 1974.

Guiso, Luigi; Sapienza, Paola \& Zingales, Luigi. Does culture affect economic outcomes?. Journal of Economic Perspectives, 2006, 20/2, p. 23-48.

Hall, Peter A. \& Lamont, Michèle (orgs.). Successful societies: how institutions and culture influence health. Nova York: Cambridge University Press, 2009.

Hannerz, Ulf. Soulside: inquiries into ghetto culture and community. Nova York: Columbia University Press, 1969.

Harding, David J. Cultural context, sexual behavior, and romantic relationships in disadvantaged neighborhoods. American Sociological Review, 2007, 72, p. 341-364.

Living the drama: community, conflict, and culture among inner-city boys. Chicago: University of Chicago Press, 2010.

Harragin, Simon. Relief and understanding of local knowledge: the case of Southern Sudan. In: Rao, Vijayendra \& Walton, Michael (orgs.). Culture and public action. Palo Alto, CA: Stanford University Press, 2004.

Hayes, Sharon. Flat broke with children: women in the age of welfare reform. Nova York: Oxford University Press, 2003.

Herrnstein, Richard J. \& Murray, Charles. The bell curve: intelligence and class structure in American life. Nova York: Free Press, 1994.

Kingdon, John. Agendas, alternatives and public policies. Boston: Little, Brown, 1984.

Kroeber, Alfred \& Kluckhohn, Clyde. Culture: a critical review of concepts and definitions. Cambridge, MA: Peabody Museum, 1952.

Lamont, Michèle. Money, morals and manners: the culture of the French and the American uppermiddle class. Chicago: University of Chicago Press, 1992.

The dignity of working men: morality and the boundaries of race, class, and immigration. Cambridge, MA: Harvard University Press, 2000.

. Responses to racism, health, and social inclusion as dimensions of successful societies. In: Hall, Peter A. \& Lamont, Michèle (orgs.). Successful societies: how institutions and culture influence health. Nova York: Cambridge University Press, 2009. 
\& Fournier, Marcel (orgs.). Cultivating differences: symbolic boundaries and the making of inequality. Chicago: University of Chicago Press, 1992.

Lamont, Michèle \& Lareau, Annette. Cultural capital: allusions, gaps, and glissandos in recent theoretical developments. Sociological Theory, 1988, 6, p. 153-168.

Lamont, Michèle \& Molnár, Viràg. The study of boundaries across the social sciences. Annual Review of Sociology, 2002, 28, p. 167-195.

Lamont, Michèle \& Small, Mario Luis. How culture matters: enriching our understanding of poverty. In: Lin, Ann C. \& Harris, David R. (orgs.). The colors of poverty. Nova York: Russell Sage Foundation, 2008, p. 76-102.

Lamont, Michèle \& Thévenot, Laurent. Rethinking comparative cultural sociology: repertoires of evaluation in France and the United States. Nova York: Cambridge University Press, 2000. Lareau, Annette. Unequal childhoods: class, race and family life. Berkeley: University of California Press, 2003.

Lewis, Oscar. La vida: a Puerto Rican family in the culture of pouerty: San Juan and New York. Nova York: Random House, 1966. Moynihan, Daniel P. The Negro family: the case for national action. Washington, DC: Office of Policy Planning and Research/U.S. Department of Labor, 1965.

Murray, Charles. Losing ground: American social policy 19501980. Nova York: Basic Books,1984.

Newman, Katherine S. No shame in my game: the working poor in the inner city. Nova York: Vintage and Russell Sage Foundation, 1999.

\& Massengill, Rebekah. The texture of hardship: qualitative sociology on poverty 1995-2005. Annual Review of Sociology, 2006, 32, p. 1-24.

O'Connor, Alice. Poverty knowledge: social science, social policy and the poor in twentieth century U. S. history. Princeton: Princeton University Press, 2001.

Ogbu, John U. Minority education and caste: the American system in cross-cultural perspective. Nova York: Academic Press, 1978. Patterson, Orlando. Taking culture seriously: a framework and an Afro-American illustration. In: Harrison, Lawrence E. 
\& Huntington, Samuel P. (orgs.). Culture matters: how values shape human progress. Nova York: Basic Books, 2000.

Polletta, Francesca. It was like a fever: storytelling in protest and politics. Chicago: University of Chicago Press, 2006.

Portes, Alejandro. Social capital: its origins and applications in modern sociology. Annual Review of Sociology, 1998, 24, p. 1-24.

Powell, Walter \& DiMaggio, Paul. The new institutionalism in organizational analysis. Chicago: University of Chicago Press, 1991.

Rao, Vijayendra \& Walton, Michael (orgs.). Culture and public action. Palo Alto, CA: Stanford University Press, 2004.

Rodman, Hyman. The lower-class value stretch. Social Forces, 1963, 42/2, p. 205-215.

Ryan, William. Blaming the victim. Nova York: Vintage Books, 1976.

Sanyal, Paromita. From credit to collective action: the role of microfinance in promoting women's social capital and normative influence. American Sociological Review, 2009, 74/4, p. 529-550.

Scott, Richard W. Institutions and organizations. Thousand Oaks, CA: Sage, 1995.

Schutz, Alfred. Collected papers. Haia: Martinus Nijhoff, 1962 (Vol. 1).

Sen, Amartya. Inequality reexamined. Nova York: Russell Sage Foundation, 1992.

Skrentny, John D. Culture and race/ethnicity: bolder, deeper, and broader. The Annals of the American Academy of Political and Social Science, 2008,619/1, p. 59-77.

Small, Mario Luis. Culture, cohorts, and social organization theory: understanding local participation in a Latino housing project. American Journal of Sociology, 2002, 108, p.1-54.

Small, Mario Luis. Villa Victoria: the transformation of social capital in a Boston barrio. Chicago: University of Chicago Press, 2004.

. Unanticipated gains: what the experience of mothers in daycares reveals about networks, inequality and well-being. Oxford, UK: Oxford University Press, 2009. 
\& Newman, Katherine S. Urban poverty after The truly disadvantaged: the rediscovery of the family, the neighborhood, and culture. Annual Review of Sociology, 2001, 27, p. 23-45.

Smith, Sandra S. Lone pursuit. Nova York: Russell Sage Foundation, 2007.

Somers, Margaret \& Block, Fred. Two hundred years of welfare debate. American Sociological Review, 2005, 70, p. 260-288. Somers, Margaret \& Gibson, Gloria. Reclaiming the epistemological "other": narrative and the social constitution of identity. In: Calhoun, Craig (org.). Social theory and the politics of identity. Cambridge, MA: Blackwell, 1994.

Steensland, Brian. Cultural categories and the American welfare state: the case of guaranteed income policy. American Journal of Sociology, 2006, 111/5, p. 1273-1326.

Steinberg, Stephen. The ethnic myth: race, class, and ethnicity in America. Nova York: Atheneum, 1981.

Stone, Deborah. Causal stories and the formation of policy agendas. Political Science Quarterly, 1989, 104, p. 281-300.

Swidler, Ann. Culture in action: symbols and strategies. American Sociological Review, 1986, 51, p. 273-286. . Responding to AIDS in Sub-Saharan Africa: culture, institutions, and health. In: Hall, Peter A. \& Lamont, Michèle (orgs.). Successful societies: how institutions and culture influence health. Nova York: Cambridge University Press.

The Annals of the American Academy of Political and Social Science, 2008, 619/1. .2009, 621/1. 2010, 629/1.

Tylor, Edward. Primitive culture: researches into the mythology, philosophy, religion, art, and custom. Londres: John Murray, 1871.

Vaisey, Stephen. What people want: rethinking poverty, culture, and educational attainment. The Annals of the American Academy of Political and Social Science, 2010, 629, p. 75-101.

Valentine, Charles A. Culture and poverty: critique and counterproposals. Chicago: University of Chicago Press, 1968. 
Van Hook, Jennifer \& Bean, Frank D. Explaining Mexican-immigrant welfare behaviors: the importance of employmentrelated cultural repertoires. American Sociological Review, 2009, 74, p. 423-444.

Waller, Maureen R. My baby's father: unmarried parents and paternal responsibility. Ithaca, NY: Cornell University Press, 2002

Whyte, William Foote. Streetcorner society. Chicago: University of Chicago Press, 1943.

Willis, Paul. Learning to labor. Nova York: Columbia University Press, 1977.

Wilson, William Julius. The truly disadvantaged: the innercity, the underclass, and public policy. Chicago: University of Chicago Press, 1987.

. When work disappears: the world of the new urban poor. Nova York: Knopf, 1996.

More than just race: being black and poor in the inner-city. Nova York: Norton, 2009a.

. The Moynihan Report and research on the black community. The Annals of the American Academy of Political and Social Science, 2009b, 621/1, p. 34-46.

Young Jr., Alford A. The minds of marginalized black men: making sense of mobility, opportunity, and life chances. Princeton: Princeton University Press, 2004. 
Resumo:

Nosso objetivo é fazer um balanço da literatura emergente sobre a relação cultura-pobreza; é identificar questões que permanecem sem resposta; e defender a posição de que o estudo judicioso da cultura, com fundamento teórico e base empírica, pode e deve ser uma componente permanente da agenda da pesquisa sobre a pobreza. Começamos identificando as razões científicas e políticas pelas quais os estudiosos da pobreza deveriam preocupar-se profundamente com a cultura. Então, abordamos uma pergunta difícil - o que é "cultura"? - e argumentamos que sociólogos e antropólogos culturais, com a finalidade de entenderem o processo de criação de significado, desenvolveram pelo menos sete instrumentos analíticos distintos, mesmo que parcialmente coincidentes, que poderiam ajudar a responder perguntas sobre casamento, educação, vizinhanças, participação em comunidades e outros tópicos centrais ao estudo da pobreza.

\section{Abstract:}

Our objective is to take stock of the budding literature on the relationship culture-poverty; identify issues that remain unanswered; and make the case that the judicious, theoretically informed, and empirically grounded study of culture can and should be a permanent component of the poverty research agenda. We begin by identifying the scholarly and policy reasons why poverty researchers should be deeply concerned with culture. We then tackle a difficult question - what is "culture"? - and make the case that sociologists and anthropologists of culture have developed at least seven different, though sometimes overlapping, analytical tools for capturing meaning-making that could help answer questions about marriage, education, neighborhoods, community participation, and other topics central to the study of poverty.

\section{Palavras-chave:}

Cultura; Pobreza; Relação cultura e pobreza; Desigualdade social; Sociologia cultural.

\section{Keywords:}

Culture; Poverty; Culture and poverty relationship; Social inequality; Cultural sociology. 